\title{
EVALUASI PELAKSANAAN SUPERVISI MANAJERIAL KEPALA UNIT PELAKSANA TEKNIS DINAS PENDIDIKAN DAN KEBUDAYAAN KECAMATAN TAPUNG HULU
}

\author{
Pharada Kresna ${ }^{1)}$ \\ Zulfan Saam ${ }^{2)}$ \\ Sudirman AS ${ }^{3)}$ \\ ${ }^{1)}$ Post Graduate Student of Riau University \\ ${ }^{2)}$ Lecturer of Education Management Study Programme PPs University of Riau \\ ${ }^{3)}$ Lecturer of Education Management Study Programme PPs University of Riau
}

\begin{abstract}
Managerial Supervision Head of Technical Implementation Unit of Education and Culture Office of Tapung Hulu Sub-district has not been maximal in supervising and supervising in the preparation and development of school-level curriculum. Managerial Supervision Head of Technical Implementation Unit of Education and Culture Office of Tapung Hulu District does not supervise and develop curriculum development. Head of UPTD does not coordinate in preparing School development plan (RPS). Preparation of Annual School Activity Plan (RKTS). As well as the School Revenue and Expenditure Budget Plan (RAPBS). Managerial Supervision Head of Technical Implementation Unit of Education and Culture Office of Tapung Hulu Sub-district has not done any assistance in preparing school curriculum, School development plan (RPS). Preparation of Annual School Activity Plan (RKTS). As well as the School Revenue and Expenditure Budget Plan (RAPBS). Managerial Supervision Head of Technical Implementation Unit of Education and Culture Office of Tapung Hulu Sub-district related to the result has not coordinated with the Principal in preparing the School Development Plan (RPS)
\end{abstract}

\section{Key Words:}

ABSTRAK: Supervisi Manajerial Kepala Unit Pelaksana Teknis Dinas Pendidikan dan Kebudayaan Kecamatan Tapung Hulu belum maksimal melakukan supervis dalam pengawasan dan pembinaan dalam penyusunan dan pengembangan kurikulum tingkat sekolah. Supervisi Manajerial Kepala Unit Pelaksana Teknis Dinas Pendidikan dan Kebudayaan Kecamatan Tapung Hulu tidak melakukan pengawasan dan pembinaan pengembangan kurikulum. Kepala UPTD tidak melakukan koordinasi dalam penyusunan Rencana pengembangan sekolah (RPS). Penyusunan Rencana Kegiatan Tahunan Sekolah (RKTS). Serta Rancangan Anggaran Pendapatan dan Belanja Sekolah (RAPBS). Supervisi Manajerial Kepala Unit Pelaksana Teknis Dinas Pendidikan dan Kebudayaan Kecamatan Tapung Hulu belum melakukan pendampingan dalam penyusunan kurikulum disekolah, Rencana pengembangan sekolah (RPS). Penyusunan Rencana Kegiatan Tahunan Sekolah (RKTS). Serta Rancangan Anggaran Pendapatan dan Belanja Sekolah (RAPBS). Supervisi Manajerial Kepala Unit Pelaksana Teknis Dinas Pendidikan dan Kebudayaan Kecamatan Tapung Hulu yang berhubungan dengan hasil belum melakukan koordinasi dengan Kepala Sekolah dalam penyusunan Rencana pengembangan sekolah (RPS).

Kata kunci: 


\section{PENDAHULUAN}

Dinas pendidikan merupakan salah satu instansi pemerintah yang bertanggung jawab mengenai berbagai hal yang berkaitan dengan pendidikan di Indonesia. Dinas pendidikan terbagi menjadi beberapa wilayah kerjanya, yaitu dinas pendidikan pusat, dinas pendidikan propinsi, dinas pendidikan kabupaten serta Unit Pelaksanan Teknis Dinas (UPTD) dinas pendidikan kecamatan. Dinas pendidikan yang berjenjang sesuai dengan wilayah kerjanya ini dibentuk untuk mempermudah tugas mereka dalam mengatur sekolah-sekolah yang berada di bawah naungannya. Untuk dinas kecamatan sekolah yang dinaunginya adalah Taman Kanakkanak dan Sekolah Dasar saja. Sedangkan di tingkat kabupaten, sekolah yang menjadi tanggung jawab mereka adalah Sekolah Dasar (SD) baik laporannya dari UPTD Dinas Pendidikan Kecamatan ataupun langsung ke Dinas Pendidikan Kabupaten, SMP atau sederajat, SMA atau sederajat serta sekolah keseteraan baik Paket A, Paket B maupun Paket C.

Sedangkan fungsi dari dinas pendidikan terbagi ke dalam beberapa poin. Yang pertama, dinas pendidikan sebagai perumus kebijakan teknis di bidang pendidikan. Jadi segala kebijakan teknis yang berkaitan dengan kebijakan di bidang pendidikan, maka dinas pendidikanlah yang bertanggung jawab untuk merumuskannya. Kedua, menyelenggarakan pelayanan umum dan pemerintahan di bidang pendidikan. Dengan kata lain fungsi dinas pendidikan adalah memastikan berlangsungnya proses belajar mengajar di sebuah sekolah. Termasuk juga segala urusan yang ada di dalamnya. Mulai dari penempatan guru yang bertugas, hingga pengangkatan kepala sekolah. Guru sebuah sekolah pengangkatannya sebagai seorang Pegawai Negeri Sipil (PNS) tergantung oleh lowongan yang dibuka di instansi ini. Begitu juga dengan kepala sekolah, untuk menjadi kepala sekolah seorang guru akan dipromosikan oleh Dinas Pendidikan tingkat kecamatan untuk Sekolah Dasar (SD), dan Dinas Pendidikan kabupaten untuk SMP dan SMA.
UPTD Pendidikan di Kecamatan merupakan bentuk perpanjangan tangan dari Kantor Dinas Pendidikan dan Kebudayaan di Tingkat Kabupaten. Sehingga segala masalah yang berkaitan dengan pendidikan dilimpahkan dari Kabupaten ke Kecamatan-Kecamatan yang ada dalam wilayah Kabupaten. Tugas UPTD Pendidikan adalah memberi petunjuk membagi tugas, membimbing, memeriksa, mengoreksi, mengawasi dan merencanakan kegiatan urusan keorganisasian dan ketatalaksanaan umum. Kepegawaian, perlengkapan, program dan pelaporan serta keuangan dalam rangka mendukung mekanisme kerja Unit Pelaksana Teknis Dinas (UPTD) Pendidikan Tingkat Kecamatan.

Fenomena lain juga dijumpai bahwa proses pindah atau mutasi siswa baik di tingkat Sekolah Dasar maupun Sekolah Menengah Pertama harus memperoleh rekomendasi dari Kepala UPTD Pendidikan Kecamatan baru dilanjutkan ke Dikdas Dinas Pendidikan Kabupaten, hal ini tentunya memberatkan dan memperpanjang birokrasi proses mutasi siswa yang notabene mengeluarkan validasi surat pindah adalah Dinas Pendidikan dan Kebudayaan Kabupaten. Proses pindah rayon bagi siswa yang tamat SD, SMP dan SMA juga harus mendapatkan rekomendasi Kepala UPTD Pendidikan dan Kebudayaan Kecamatan baru dilanjutkan ke Dinas Pendidikan dan Kebudayaan Kabupaten, hal ini juga menjadi syarat pengurusan surat pindah rayon yang dikeluarkan Dinas Pendidikan dan Kebudayaan Kabupaten.

Berdasarkan fenomena di atas, menunjukkan bahwa keberadaan UPTD Pendidikan belum dapat menyelesaikan permasalahan dalam ruang lingkup SD dan TK sehingga terkesan bahwa UPTD Pendidikan sebagai perpanjangan tangan dari Dinas Pendidikan Kebudayaan Kabupaten belum dapat berfungsi sebagaimana mestinya. Kondisi ini menjadi alasan ketertarikan penulis untuk melakukan suatupenelitian denganjudul "Evaluasi Pelaksanaan Supervisi Manajerial Kepala Unit Pelaksana Teknis Dinas Pendidikan dan Kebudayaan Kecamatan Tapung Hulu”. 
Fokus dalam penelitian ini yaitu bagaimana Evaluasi Pelaksanaan Supervisi Manajerial Kepala Unit Pelaksana Teknis Dinas Pendidikan dan Kebudayaan Kecamatan Tapung Hulu Dengan Pendekatan Context Input Process Product berdasarkan perencanaan yang telah dibuat. Sedangkan yang menjadi sub fokus adalah a) context yaitu berkaitan dengan kebutuhan yang akan dicapai oleh program kerja UPTD Pendidikan dan perumusan tujuan program kerja UPTD Pendidikan, b) input yaitu berkaitan dengan pengaturan keputusan, menentukan sumber yang ada, alternatif apa yang diambil, apa rencana dan strategi untuk mencapai kebutuhan. Bagaimana prosedur kerja untuk mencapainya, c) proses berkaitan dengan sampai sejauh mana rencana telah diterapkan? Apa yang harus direvisi?, Begitu per-tanyaan tersebut terjawab, prosedur dapat dimonitor, dikontrol dan diperbaiki. d) output berkaitan dengan hasil yang telah dicapai apa yang dilakukan setelah program berjalan.

Adapun perumusan masalah yang diajukan dalam penelitian ini yaitu:

1. Bagaimanakah Evaluasi Pelaksanaan Supervisi Manajerial Kepala Unit Pelaksana Teknis Dinas Pendidikan dan Kebudayaan Kecamatan Tapung Hulu yang berhubungan dengan Context?

2. Bagaimanakah Evaluasi Pelaksanaan Supervisi Manajerial Kepala Unit Pelaksana Teknis Dinas Pendidikan dan Kebudayaan Kecamatan Tapung Hulu yang berhubungan dengan Input?

3. Evaluasi Pelaksanaan Supervisi Manajerial Kepala Unit Pelaksana Teknis Dinas Pendidikan dan Kebudayaan Kecamatan Tapung Hulu yang Berhubungan dengan Proses?

4. Bagaimanakah Evaluasi Pelaksanaan Supervisi Manajerial Kepala Unit Pelaksana Teknis Dinas Pendidikan dan Kebudayaan Kecamatan Tapung Hulu yang berhubungan dengan Hasil Program?

Sesuai dengan fokus dan subfokus penelitian, maka tujuan penelitian ini mengungkapkan dan menganalisis secara jelas dan cermat beberapa hal yaitu:

1. Untuk Menganalisis Evaluasi Pelaksanaan Supervisi Manajerial Kepala Unit Pelaksana Teknis Dinas Pendidikan dan Kebudayaan Kecamatan Tapung Hulu yang berhubungan dengan Context.

2. Untuk Menganalisis Evaluasi Pelaksanaan Supervisi Manajerial Kepala Unit Pelaksana Teknis Dinas Pendidikan dan Kebudayaan Kecamatan Tapung Hulu yang berhubungan dengan Input.

3. Untuk Menganalisis Evaluasi Pelaksanaan Supervisi Manajerial Kepala Unit Pelaksana Teknis Dinas Pendidikan dan Kebudayaan Kecamatan Tapung Hulu yang berhubungan dengan Proses.

4. Untuk Menganalisis Evaluasi Pelaksanaan Supervisi Manajerial Kepala Unit Pelaksana Teknis Dinas Pendidikan dan Kebudayaan Kecamatan Tapung Hulu yang berhubungan dengan Hasil Program.

Secara umum istilah evaluasi dapat disamakan dengan penafsiran (appraisal), pemberian angka (rating) dan penilaian (assesment). Dalam arti spesifik evaluasi berkenaan dengan produksi informal mengenai nilai atau manfaat hasil kebijakan.

Evaluasi biasanya ditujukan untuk menilai sejauh mana keefektifan kebijakan publik guna dipertanggungjawabkan kepada konstituennya. Sejauh mana tujuan dicapai. Evaluasi diperlukan untuk melihat kesenjangan antara harapan dan kenyataan.

Kata evaluasi berasal dari bahasa Inggris Evaluation yang memiliki arti : Penilaian. Kalau kita lihat dari segi istilah sebagaimana dijelaskan Sudijono bahwa Edwind Wandt dan Gerald W. Brown dalam Sudijono, mengemukakan: “ Evaluation refe to the act or process to determining the value of something”. Menurut definisi ini, maka istilah evaluasi itu menunjuk kepada atau mengandung pengertian: Suatu tindakan atau suatu proses untuk menentukan nilai dari sesuatu. 
Arikunto, mengemukakan bahwa mengadakan evaluasi adalah melakukan pengukuran dan penilaian. Mengukur adalah membandingkan sesuatu dengan satu ukuran. Pengukuran bersifat kuantitatif. Sedangkan menilai adalah mengambil suatu keputusan terhadap sesuatu dengan ukuran baik buruk. Penilaian bersifat kualitatif. Dalamistilah asingnya, pengukuran adalah measurement, sedang penilaian adalah evaluation. Dari kata evaluation inilah diperoleh kata Indonesia evaluasi yang berarti menilai (tetapi dilakukan dengan mengukur terlebih dahulu). Alat evaluasi juga dikenal dengan instrumen evaluasi. Dalam kegiatan evaluasi, fungsi alat juga untuk memperoleh hasil yang lebih baik sesuai dengan kenyataan yang dievaluasi dan ada dua tekhnik evaluasi, yaitu tekhnik nontes dan tekhnik tes.

Tujuan pokok evaluasi bukanlah untuk menyalah nyalahkan, melainkan untuk melihat seberapa besar kesenjangan antara pencapaian dan harapan suatu kebijakan publik. Tugas selanjutnya adalah bagaimana mengurangi atau menutup kesenjangan tersebut. Jadi, evaluasi kebijakan publik harus dipahami sebagai suatu yang bersifat positif. Evaluasi bertujuan untuk mencari kekurangan dan menutup kekurangan.

Banyak model evaluasi yang dikemukakan oleh para ahli. Arifin mengelompokkan modelmodel evaluasi program menjadi kelompok yaitu model evaluasi kuantitif dan model evaluasi kualitatif. Model evaluasi kuantitatif terdiri dari model Tyler, model Horfil Tyler dan Maquire, model pendekatan sistem Alkin, model evaluasi Scriven's Formative-Sumative Model; CIPP Model (Sufflebeam); CSE-UCLA Model; Stake's Countenance Stake Model; Sciven's Goal Free Model; Stake's Responsive Model”.

Lebih lanjut Arifin mengemukakan model CIPP membagi empat jenis kegiatan evaluasi yaitu:

a. Context Evaluation to serve planning decision. Konteks evaluasi ini membantu merencanakan keputusan, menentukan kebutuhan yang akan dicapai oleh program dan merumuskan tujuan program. b. Input evaluation, structuring decision. Evaluasi ini menolong mengatur keputusan, menentukan sumber-sumber yang ada, alternatif apa yang diambil, apa rencana dan strategi untuk mencapai kebutuhan. Bagaimana prosedur kerja untuk mencapainya.

c. Process Evaluation, to serve implementing decision. Evaluasi proses untuk membantu mengimplimentasikan keputusan. Sampai sejauh mana rencana telah diterapkan? Apa yang harus direvisi? Begitu per-tanyaan tersebut terjawab, prosedur dapat dimonitor, dikontrol dan diperbaiki.

d. Product Evaluation, to serve recycling decision. Evaluasi produk untuk menolong keputusan selanjutnya. Apa hasil yang telah dicapai? apa yang dilakukan setelah program berjalan? Huruf pertama dari konteks evaluasi dijadikan ringkasan CIPP model ini terkenal dengan nama model CIPP oleh Stafflebeam.

Secara bahasa supervisi berarti mengamati, mengawasi, atau membimbing kegiatan-kegiatan yang dilakukan oleh orang lain dengan maksud untuk mengadakan perbaikan. Supervisi berasal dari kata "super" artiny a lebih atau atas, dan "vision" artinya melihat atau meninjau.

Menurut Ngalim Purwanto, supervisi adalah suatu aktivitas pembinaan yang direncanakan untuk membantu para guru dan pegawai sekolah lainnya dalam melakukan pekerjaan mereka secara efektif. Jadi supervisi merupakan upaya melakukan perbaikan kepala sekolah dalam memberikan masukan dan arahan oleh supervisor, sebagaimana dikutip Piet. A. Sahertian, supervis adalah "suatu usaha menstimulasi, mengkoordinasi dan membimbing secara kontinu pertumbuhan guru-guru di sekolah baik secara individual maupun secara kolektif, agar lebihmengerti dan lebih efektif dalam mewujudkan seluruh fungsi pengajaran.

Suatu organisasi harus ada orang yang mengkoordinasikan semua kegiatan yang ada, membuat dan mengambil keputusan, 
mengalokasikan sumber dana untuk mencapai sasaran. Orang yang melakukan koordinasi terhadap kegiatan-kegiatan dalam organisasi tersebut disebut dengan manajer. Sebagian ahli berpendapat bahwa administrasi sama dengan manajemen bahwa dalam pemakaiannya secara umum adminitrasi diartikan dengan manajemen dan administrator sama dengan manajer

Menurut Handoko secara umum setiap orang yang mempunyai tanggung jawab atas bawahan dan sumber-sumber daya organisasi lainnya disebut sebagai manajer. Seperti halnya manajemen dapat diketemukan disemua organisasi manusia, manajer ada dalam semua tipe organisasi.

Manajer menurut Handoko dapat diklasifikasikan dengan dua cara : menurut tingkatan mereka dalam organisasi-rendah, menengah dan tinggi dan kegiatan-kegiatan organisasi untuk mana mereka bertanggung jawab-manajer umum dan fungsional.

Dalam sebuah organisasi, seorang manajer dituntut mempunyai kemampuan manajerial untuk menjalankan fungsi-fungsi manajemen dalam mencapai tujuan. kemampuan manajerial merupakan kompetensi yang harus dimiliki seseorang untuk mendayagunakan sumber daya suatu organisasi dalam mencapai tujuan. Kemampuan manajerial bersifat praktis operasional untuk menggerakkan sumber daya organisasi supaya berdaya guna dan berhasil guna.

Kemampuan (Ability) adalah kecakapan atau potensi seseorang individu untuk menguasai keahlian dalam melakukan atau mengerrjakan beragam tugas dalam suatu pekerjaan atau suatu penilaian atas tindakan seseorang.

Menurut Winardi definisi Kemampuan atau keterampilan manajerial adalah suatu kemampuan seseorang dalam mengelola sumber daya organisasi berdasarkan kompetisi yang ditetapkan dalam rangka mencapai tujuan yang telah ditentukan. Keterampilan manajerial diperlukan untuk melaksanakan tugas manajerial secara efektif akan tetapi jenis keterampilan berbeda menurut tingkatan manajer dalam organisasi.

\section{METODOLOGI PENELITIAN}

Berdasarkan tujuan penelitian ini, maka penelitian ini menggunakan pendekatan deskriptif kualitatif. Pendekatan kualitatif dipandang lebih relevan untuk digunakan di dalam mengamati dan menganalisa fenomena-fenomena pada manajerial UPTD Pendidikan Kecamatan Tapung Hulu Kabupaten Kampar. Pendekatan kualitatif dilaksanakan sebagai upaya memahami situasi tertentu dengan bentuk penelitian studi kasus. Studi kasus adalah penelitian yang dilakukan secara intensif, terinci dan mendalam terhadap suatu organisasi, lembaga atau gejala tertentu.

Sebelum peneliti melakukan pemilihan informan, maka terlebih dahulu ditetapkan situasi sosial atau site penelitian, yang merupakan tempat di mana permasalahan atau fenomena sosial yang akan diteliti betul-betul ada. Untuk mendapatkan informasi yang benar valid, maka di dalam memilih informasi dapat di lakukan melalui wawancara pendahuluan, sebelum melakukan penelitian. Informan dalam penelitian ini adalah Kepala Dinas Pendidikan Kabupaten Kampar, Kepala UPTD Pendidikan Kecamatan Tapung Hulu, 1 orang Kepala Sekolah Dasar, 1 orang guru PAUD dan 1 orang guru Sekolah Dasar Negeri.

\section{HASIL DAN PEMBAHASAN}

1. Evaluasi Pelaksanaan Supervisi Manajerial Kepala Unit Pelaksana Teknis Dinas Pendidikan dan Kebudayaan Kecamatan Tapung Hulu dalam Penyusunan Kurikulum Tugas pengkoordinasian yang mesti dilaksanakan oleh Unit Pelaksana Teknis (UPT) Dinas Pendidikan dan Kebudayaan Tapung Hulu antara lain adalah sebagai berikut:

a. Melakukan Koordinasi dengan Pengawas TK. SD/MI, SLTP/MTS, SMU/SMK/ MAN se Kecamatan Tapung Hulu.

b. Memberikan rekomendasi permohonan mutasi dan tugas/izin belajar bagi guru serta pegawai kantor untuk melanjutkan pendidikan. 
c. Memberikan rekomendasi perizinan dibidang pendidikan luar sekolah sesuai dengan ketentuan yang berlaku

d. Memberikan rekomendasi usul pemberian bantuan kepada kelompok masyarakat atau lembaga penyelenggara pendidikan luar sekolah

e. Menyampaikan usulan pembukaan TK. SD/ MI, SLTP/MTS, SMU/SMK/MAN sebagai bahan masukan bagi Kepala Dinas

f. Merekomendasikan usulan mutasi siswa TK. SD/MI, SLTP/MTS, SMU/SMK/MAN sesuai dengan ketetuan yang berlaku.

g. Melakukan kerja sama lintas sektoral dengan Instansi Pemerintah, swasta dan masyarakat dalam Pendidikan Luar Sekolah

h. Mengajukan usul rencana dan program rutin dan pembangunan

Berdasarkan penjelasan dari guru PAUD menjelaskan bahwa kepala UPTD belum melakukan program kerjanya sesuai dengan penyusunan kurikulum, karena kepala UPTD selalu mengutus pengawas dalam melakukan pengawasan, yang semestinya dia melakukan pendampingan serta melakukan rapat koordinasi dengan tim penyusunan kurikulum, namun yang terjadi kurikulum yang sudah selesai yang selalu disampaikan oleh pihak sekolah kepada UPTD, tidak ada rapat koordinasi yang dilakukan oleh kepala UPTD.

Berdasarkan data di atas kepala UPTD tidak berwenang dalam menetapkan kurikulum sekolah, karena kurikulum sudah ditetapkan oleh pemerintah, namun kepala UPTD berdasarkan program kerjanya berkewajiban melakukan pendampingan penyusunan Kurikulum Sekolah, rapat koordinasi dengan tim penyusun Kurikulum Sekolah, memantau proses penyusunan Kurikulum Sekolah, verifikasi draf Kurikulum Sekolah, dan fasilitasi pengesahan Kurikulum Sekolah. Namun semua program kerja tersebut tidak semuanya dilakukan oleh kepala UPTD, namun yang terjadi kepala UPTD selalu mempercayakan kepada pengawas yang bertugas di UPTD dalam melakukan program UPTD yang berhubungan dengan penyusunan kurikulum sekolah. Sehingga banyak sekolah yang kurikulumnya tidak sesuai dengan kebutuhan sekolah bersangkutan karena tidak ada koordinasi yang dilakukan oleh kepala UPTD sehingga hasil kurikulum yang disusun oleh sekolah-sekolah tidak sesuai dengan kebutuhan sekolah.

2. Evaluasi Pelaksanaan Supervisi Manajerial Kepala Unit Pelaksana Teknis Dinas Pendidikan dan Kebudayaan Kecamatan Tapung Hulu yang berhubungan dengan Rencana Pengembangan Sekolah

1. Berkoordinasi dengan UPTD pendidikan dalam penyusunan dan pengembangan Rencana Pengembangan Sekolah

Berdasarkan hasil penelitian menunjukkan bahwa manajerial Kepala Unit Pelaksana Teknis Dinas Pendidikan dan Kebudayaan Kecamatan Tapung Hulu yang berhubungan dengan input, Berdasarkan data yang disampaikan oleh Kepala Dinas Pendidikan Kabupaten Kampar. Kepala UPTD dalam membuat Rancangan Pengembangan Sekolah (RPS), karena kepala UPTD sebagai perpanjangan tangan Dinas Pendidikan di kecamatan tentu memiliki data-data yang detail mengenai sekolah yang dibawah pengawasannya, karena kepala UPTD yang bertugas telah dibekali dengan program-program yang dirancang untuk melakukan tugas sesuai denga program tersebut.

Kepala sekolah melakukan koordinasi dengan Kepala UPTD Pendidikan dalam penyusunan Rencana pengembangan sekolah (RPS), dengan melakukan koordinasi diketahui apa yang dibutuhkan oleh sekolah, karena semua sarana diberasal dari anggaran pemerintah, jadi koordinasi antara Kepala Sekolah dengan Kepala UPTD Pendidikan itu penting.

2. Berkoordinasi dengan UPTD pendidikan dalam penyusunan Rencana Kegiatan Tahunan Sekolah (RKTS)

Berdasarkan hasil penelitian diketahui bahwa Kepala Sekolah melakukan koordinasi dengan Kepala UPTD pendidikan dalam Penyusunan Rencana Kegiatan Tahunan Sekolah 
(RKTS). Karena Penyusunan Rencana Kegiatan Tahunan Sekolah yang disusun oleh Kepala Sekolah belum tentu mendapatkan persetujuan dari Kepala UPTD diharapkan Penyusunan Rencana Kegiatan Tahunan Sekolah sudah bisa diterima dan dilaksanakan disekolah.

3. Berkoordinasi dengan UPTD pendidikan dalam penyusunan Rencana Anggaran Pendapatan dan Belanja Sekolah (RAPBS) menjadi APBS)

Berdasarkan hasil penelitian diketahui bahwa dalam Penyusunan Anggaran Pendapatan dan Belanja Sekolah Kepala Sekolah melakukan Koordinasi dengan Kepala UPTD. Dalam penyusunan anggaran pendapatan dan belanja sekolah mesti dilaporkan oleh kepala sekolah, karena dalam penyusunan tersebut ada aturan yang mesti dipatuhi oleh pihak sekolah.

Personil sekolah dan Kepala sekolah melakukan koordinasi dengan Kepala UPTD Pendidikan dalam penyusunan Rencana pengembangan sekolah (RPS), dengan melakukan koordinasi diketahui apa yang dibutuhkan oleh sekolah, karena semua sarana diberasal dari anggaran pemerintah, jadi koordinasi antara Kepala Sekolah dengan Kepala UPTD Pendidikan itu penting.

Berdasarkan hasil penelitian diketahui bahwa dalam Penyusunan Anggaran Pendapatan dan Belanja Sekolah Personil sekolah dan Kepala Sekolah melakukan Koordinasi dengan Kepala UPTD. Dalam penyusunan anggaran pendapatan dan belanja sekolah mesti dilaporkan oleh kepala sekolah, karena dalam penyusunan tersebut ada aturan yang mesti dipatuhi oleh pihak sekolah.

3. Evaluasi Pelaksanaan Supervisi Manajerial Kepala Unit Pelaksana Teknis Dinas Pendidikan dan Kebudayaan Kecamatan Tapung Hulu yang berhubungan dengan proses

a. Kurikulum Sekolah yang telah disahkan oleh pejabat yang berwenang

Pendampingan penyusunan Kurikulum Sekolah Berdasarkan hasil penelitian diketahui bahwa dalam penyusunan kurikulum disekolah tidak mesti ada pendampingan dari UPTD, namun UPTD menerima kurikulum yang dibuat oleh sekolah, dan UPTD hanya melakukan koreksi dan memeriksa kurikulum yang disusun disekolah oleh para guru. Jika kurikulum tersebut sudah dapat diterima serta kepala UPTD mensahkan kurikulum tersebut. Artinya kepala sekolah melaporkan hasil penyusunan kurikulum yang dilakukan oleh sekolah. Dalam Penyusunan Anggaran Pendapatan dan Belanja Sekolah Personil sekolah dan Kepala Sekolah melakukan Koordinasi dengan Kepala UPTD. Dalam penyusunan anggaran pendapatan dan belanja sekolah mesti dilaporkan oleh kepala sekolah, karena dalam penyusunan tersebut ada aturan yang mesti dipatuhi oleh pihak sekolah. Namun Penyusunan kurikulum sekolah Kepala UPTD pengawasan terhadap penyusunan kurikulu, kepala sekolah melaporkan kurikulum yang disusun untuk dapat disahakan oleh kepala UPTD setelah melakukan pengecekan.

Penyusunan kurikulum sekolah Kepala UPTD pengawasan terhadap penyusunan kurikulu, kepala sekolah melaporkan kurikulum yang disusun untuk dapat disahakan oleh kepala UPTD setelah melakukan pengecekan. Dan Penyusunan kurikulum sekolah Kepala UPTD pengawasan terhadap penyusunan kurikulu, kepala sekolah melaporkan kurikulum yang disusun untuk dapat disahakan oleh kepala UPTD setelah melakukan pengecekan.

Penyusunan kurikulum sekolah Kepala UPTD pengawasan terhadap penyusunan kurikulu, kepala sekolah melaporkan kurikulum yang disusun untuk dapat disahakan oleh kepala UPTD setelah melakukan pengecekan. Dan Penyusunan kurikulum sekolah Kepala UPTD pengawasan terhadap penyusunan kurikulu, kepala sekolah melaporkan kurikulum yang disusun untuk dapat disahakan oleh kepala UPTD setelah melakukan pengecekan. Penyusunan kurikulum sekolah Kepala UPTD pengawasan terhadap penyusunan kurikulu, kepala sekolah melaporkan kurikulum yang disusun untuk dapat disahakan oleh kepala UPTD setelah melakukan pengecekan. 
b. Rencana Kegiatan Tahunan Sekolah (RKTS)

Penyusunan kurikulum sekolah Kepala UPTD pengawasan terhadap penyusunan kurikulu, kepala sekolah melaporkan kurikulum yang disusun untuk dapat disahakan oleh kepala UPTD setelah melakukan pengecekan. Penyusunan kurikulum sekolah Kepala UPTD pengawasan terhadap penyusunan kurikulu, kepala sekolah melaporkan kurikulum yang disusun untuk dapat disahakan oleh kepala UPTD setelah melakukan pengecekan.

Penyusunan Anggaran Pendapatan dan Belanja Sekolah Personil sekolah dan Kepala Sekolah melakukan Koordinasi dengan Kepala UPTD. Dalam penyusunan anggaran pendapatan dan belanja sekolah mesti dilaporkan oleh kepala sekolah, karena dalam penyusunan tersebut ada aturan yang mesti dipatuhi oleh pihak sekolah. Penyusunan Anggaran Pendapatan dan Belanja Sekolah Personil sekolah dan Kepala Sekolah melakukan Koordinasi dengan Kepala UPTD. Dalam penyusunan anggaran pendapatan dan belanja sekolah mesti dilaporkan oleh kepala sekolah, karena dalam penyusunan tersebut ada aturan yang mesti dipatuhi oleh pihak sekolah.

Penyusunan Anggaran Pendapatan dan Belanja Sekolah Personil sekolah dan Kepala Sekolah melakukan Koordinasi dengan Kepala UPTD. Dalam penyusunan anggaran pendapatan dan belanja sekolah mesti dilaporkan oleh kepala sekolah, karena dalam penyusunan tersebut ada aturan yang mesti dipatuhi oleh pihak sekolah. Penyusunan Anggaran Pendapatan dan Belanja Sekolah Personil sekolah dan Kepala Sekolah melakukan Koordinasi dengan Kepala UPTD. Dalam penyusunan anggaran pendapatan dan belanja sekolah mesti dilaporkan oleh kepala sekolah, karena dalam penyusunan tersebut ada aturan yang mesti dipatuhi oleh pihak sekolah.

Penyusunan Anggaran Pendapatan dan Belanja Sekolah Personil sekolah dan Kepala Sekolah melakukan Koordinasi dengan Kepala UPTD. Dalam penyusunan anggaran pendapatan dan belanja sekolah mesti dilaporkan oleh kepala sekolah, karena dalam penyusunan tersebut ada aturan yang mesti dipatuhi oleh pihak sekolah.

\section{Evaluasi Pelaksanaan Supervisi Manajerial Kepala Unit Pelaksana Teknis Dinas Pendidikan dan Kebudayaan Kecamatan Tapung Hulu yang Berhubungan dengan Hasil Program}

a. Kurikulum Sekolah

Personil sekolah dan Kepala sekolah melakukan koordinasi dengan Kepala UPTD Pendidikan dalam penyusunan Rencana pengembangan sekolah (RPS), dengan melakukan koordinasi diketahui apa yang dibutuhkan oleh sekolah, karena semua sarana diberasal dari anggaran pemerintah, jadi koordinasi antara Kepala Sekolah dengan Kepala UPTD Pendidikan itu penting.

\section{b. Rencana Pengembangan Sekolah (RPS)}

Personil sekolah dan Kepala sekolah melakukan koordinasi dengan Kepala UPTD Pendidikan dalam penyusunan Rencana pengembangan sekolah (RPS), dengan melakukan koordinasi diketahui apa yang dibutuhkan oleh sekolah, karena semua sarana diberasal dari anggaran pemerintah, jadi koordinasi antara Kepala Sekolah dengan Kepala UPTD Pendidikan itu penting.

\section{c. Rencana Kegiatan Tahunan Sekolah (RKTS)}

Kepala UPTD berkewajiban melakukan Pembinaan terhadap Penyusunan Rencana Kegiatan Tahunan Sekolah (RKTS). Karena pembinaan disini gunanya untuk melihat setiap kegiatan yang dilakukan sekolah apakah sesuai dengan ketentuan yang telah ditetapkan dalam Penyusunan Rencana Kegiatan Tahunan Sekolah (RKTS).

d. Rencana Anggaran Pendapatan dan Belanja Sekolah (RAPBS) menjadi APBS

Kepala UPTD Dinas Pendidikan dan Kebudayaan Kecamatan Tapung Hulu sebagai perpanjangan tangan dari Dinas Pendidikan dan Kebudayaan Kabupaten Kampar memiliki tanggungjawab dalam meningkatkan mutu pendidikan di Kecamatan Tapung Hulu dengan 
melakukan supervisi terhadap kepala sekolah dan guru-guru yang ada di Kecamatan Tapung dari tingkat Taman kanak-kanak sampai Sekolah Menengah Atas.

Supervisi yang dilakukan oleh Kepala UPTD Dinas Pendidikan dan Kebudayaan Tapung Hulu merupakan pembinaan dan pengawasan penyusunan kurikulum, pengesahannya, proses penyusunan kurikulum, perifikasi draf kurikulum, penyusunan rancangan pengembangan sekolah, rancangan kegiatan tahunan sekolah, Penyusunan Rancangan Anggaran Pendapatan dan Belanja Sekolah.

Kepala UPTD Dinas Pendidikan dan Kebudayaan Tapung Hulu berdasarkan datadata yang di atas belum melakukan supervisi Menajerial sebagaimana program-program kerjanya dalam melakukan pengawasan dan pembinaan penyusunan kurikulum oleh sekolah, penyusunan pengambangan sekolah, Rancangan Anggaran Pendapatan dan Belanja Sekolah, ini terlihat bahwa Kepala UPTD selalu mewakili kepada pengawas dalam melakukan supervisi setiap propgram-program yang meningkatkan mutu pendidikan di Kecamatan Tapung Hulu.

Oleh karena itu Kepala UPTD Pendidikan dan Kebudayaan Kecamtan Tapung Hulu belum melaksanakan program kerjanya sesuai dengan aturan yang berlaku, maka secara tidak langsung Kepala UPTD Kecamatan Tapung tidak mempu untuk melakukan supervisi untuk meningkatkan mutu pendidikan di Kecamatan Tapung Hulu. Agar mutu pendidikan semakin baik maka dinas pendidikan mesti memperhatikan Kepala UPTD yang ditunjuk untuk menjadi perwakilannya di setiap Kecamatan yang ada di Kabupaten Kampar.

Maka keputusan yang dapat diambil dari penelitian ini bahwa Kepala UPTD belum melaksanakan supervisi menajerial dalam penyusunan kurikulum sekolah, penyusunan pengambangan sekolah, Rancangan Anggaran Pendapatan dan Belanja Sekolah. Kepala UPTD sebagai perpanjangan tangan dari Dinas Pendidikan bisa melaksanakan tugas dengan baik untuk meningkatkan mutu pendidikan di
Kecamatan Tapung Hulu khususnya dan kampar pada umumnya.

\section{SIMPULAN DAN SARAN}

a. Supervisi Manajerial Kepala Unit Pelaksana Teknis Dinas Pendidikan dan Kebudayaan Kecamatan Tapung Hulu yang berhubungan dengan context. Bahwa Kepala UPTD belum maksimal melakukan supervis dalam pengawasan dan pembinaan dalam penyusunan dan pengembangan kurikulum tingkat sekolah, namun yang melaksanakan supervis dilakukan oleh pengawas yang ada di UPTD untuk melakukan koordinasi dengan kepala sekolah mengenai kebijakan pendidikan disekolahnya.

b. Supervisi Manajerial Kepala Unit Pelaksana Teknis Dinas Pendidikan dan Kebudayaan Kecamatan Tapung Hulu yang berhubungan dengan input. Kepala UPTD tidak terlibat dalam pengembangan kurikulum di sekolah, namun melakukan supervisi dalam pengembangan kurikulum disekolah, Kepala UPTD tidak melakukan pengawasan dan pembinaan pengembangan kurikulum. Kepala UPTD tidak melakukan koordinasi dalam penyusunan Rencana pengembangan sekolah (RPS). Penyusunan Rencana Kegiatan Tahunan Sekolah (RKTS). Serta Rancangan Anggaran Pendapatan dan Belanja Sekolah (RAPBS).

c. Supervisi Manajerial Kepala Unit Pelaksana Teknis Dinas Pendidikan dan Kebudayaan Kecamatan Tapung Hulu belum melakukan pendampingan dalam penyusunan kurikulum disekolah, namun UPTD menerima kurikulum yang dibuat oleh sekolah, dan UPTD hanya melakukan koreksi dan memeriksa kurikulum yang disusun disekolah oleh para guru. Jika kurikulum tersebut sudah dapat diterima serta kepala UPTD mensahkan kurikulum tersebut. Dan begitu juga dengan Rencana pengembangan sekolah (RPS). Penyusunan Rencana Kegiatan Tahunan Sekolah (RKTS). Serta Rancangan Anggaran Pendapatan dan Belanja Sekolah (RAPBS). 
d. Supervisi Manajerial Kepala Unit Pelaksana Teknis Dinas Pendidikan dan Kebudayaan Kecamatan Tapung Hulu yang berhubungan dengan hasil program bahwa Kepala UPTD Pendidikan dan Kebudayaan Kecamatan Tapung Hulu belum melakukan koordinasi dengan Kepala Sekolah dalam penyusunan Rencana pengembangan sekolah(RPS), dan melakukan koordinasi apa yang dibutuhkan oleh sekolah, karena semua sarana diberasal dari anggaran pemerintah, jadi koordinasi antara Kepala Sekolah dengan Kepala UPTD Pendidikan itu penting.

\section{Saran}

a. UntukUPTD

Kepada kepala UPTD selaku Kecamatan Tapung Hulu agar memperhatikan setiap kegiatan yang dilakukan disekolah-sekolah yang ada diwilayanya, baik fisik, sarana prasarana serta pengembangan kurikulum serta anggaran pendidikannya.

b. Kepala Sekolah

Kepada kepala sekolah untuk selalu melakukan koordinasi dengan Kepala UPTD dalam setiap kegiatan sekolah baik penyusunan anggaran, pengembanga kurikulum, pengembangan sekolah serta pembangunan sarana prasarana.

c. Peneliti Selanjutnya

Kepada peneliti selanjutnya disarankan untuk meneliti atau mengevaluasi koordinasi antara Kepala Seolah dengan Kepala UPTD dalam meningkatkan mutu pendidikan.

\section{DAFTAR PUSTAKA}

Achmad. Sistem Manajemen Kinerja (Performance Management System), Panduan Praktis untuk Merancang dan Meraih Kinerja Prima. Jakarta. PT. Gramedia. 2004

Anas Sudijono. Pengantar Evaluasi Pendidikan. Jakarta. Rajawali Pers. 2009

Budi Winarno. Teori dan Proses Kebijakan Publik, Media Press, Yogyakarta.2002

Griffin. Manajemen. Jilid 1 Edisi ke-tujuh. Jakarta. Erlangga. 2004
Husaini Usman. ManajemenTeori ,Praktik dan Riset Pendidikan. Jakarta. Bumi Aksara. 2013

Jennifer M.George \& Gareth R.Jones. Understanding And Managing Organizational Behavior. Fourth edition, Pearson Prentice hall. 2005

Moleong. Metode Penelitian Kualitatif. Bandung. Rosda Karya. 2008

Muhammad Rohman dan Sofan Amri. Manajemen Pendidikan, analisis dan solusi terhadap kinerja manajemen kelas dan strategi pengejaran yang efektif. Jakarta. PT. Prestasi Pustakaraya. 2012

Zaenal Arifin. Evaluasi Pembelajaran, Prinsip, Teknik dan Prosedur. Bandung. Rosda. 2009

William N. Dunn. Pengantar Analisis Kebijakan Publik, Yogyakarta:Gadjah Mada University Press,2000

Riant Nugroho. Public Polity. Jakarta: PT.Gramedia. 2008

Riant Nugroho. Kebijakan Publik Formulasi, Implementasi dan Evaluasi, Jakarta. Elex Media Komputindo.2008

Sudjana. Manajemen Program Pendidikan. Bandung. Falah Production. 2000

Stephen Robin. Perilaku Organisasi, Edisi ke 10. Jakarta. PT. Indeks Kelompok Gramedia. 2006

Suharsimi Arikunto. Prosedur Penelitian Suatu pendekatan Praktek. Jakarta: PT.Rineka Cipta.1999

Suharsimi Arikunto. Dasar-dasar Evaluasi Pendidikan. Jakarta. Bumi Aksara. 2003

T. Hani Handoko. Manajemen Edisi 2. Yogyakarta. BPFE. 2008

Wahyudi. Kepemimpinan Kepala Sekolah dalam Organisasi Pembelajar, Bandung. Alfabeta. 2009

UPTD Pendidikan Kecamatan Tapung Hulu, Maret 2016

http://hadfi-ibadurrahman.blogspot.com/2012/ 01/analisis-data-penelitian-kualitatif dan.html?m=1. diakses17 Maret 2016 jam 13.24 wib 